\title{
Alçı ile tespitte temel prensipler (çorap, pamuk nasıl sarılır, kaç kat olmalı)
}

\section{Basic principles of casting and splinting}

\author{
Yusuf Alper Katı, H. Yalçın Yüksel \\ Sağlık Bilimleri Üniversitesi, Antalya Eğitim ve Araştırma Hastanesi Ortopedi Kliniği, Antalya
}

\begin{abstract}
Kırıklar, yumuşak doku hasarları ve bazı kas iskelet sistemi hastalıklarının geçici tespiti veya tedavisi, atel ya da sirküler alçı kullanımını gerektirir. Atel, sirküler yapıda olmayan bir tespit materyalidir, hızlı ve kolay uygulanır; dolayısıyla, kırık, çıkık, burkulma ve diğer ortopedik yaralanma gibi akut durumlarda idealdir. Sirküler alçı ise çepeçevredir. Bu sayede daha iyi bir tespit sağlar ve kırığın kalıcı tedavisi için de kullanılır; ancak daha çok komplikasyona yol açabilir. Alçı ile tespit süresini en uygun düzeyde tutmak, en az komplikasyon ile en yararlı sonucu elde etmeyi sağlar. Alçı veya atel kullanılırken gerekli immobilizasyondan daha fazlası komplikasyonlara yol açar. Bu yüzden, ortopedi ve travmatolojide uygun endikasyon, uygun teknik ve dikkatli izlem hasta tedavisini başarılı kılar.
\end{abstract}

Anahtar sözcülkler: alçı; atel; uygulama tekniği; komplikasyonlar
Fixation and treatment of musculoskeletal conditions like fractures, soft tissue damages or some musculoskeletal diseases require the use of splints or casts. Splints are faster and easier to apply, and they are non-circumferential immobilizers. Therefore, splints are ideal for management of a variety of acute musculoskeletal conditions in which swelling is anticipated such as fractures, dislocations, sprains, and other orthopaedic cases. On the other hand, casts are circumferential immobilizers. Therefore, casts provide better stabilization, and they are used in definitive fracture management; but they have higher complication rates. The use of casts and splints is generally limited to the short term to maximize benefits while minimizing the complications. More than necessary immobilization while using casts or splints lead to complications. Because of this we need to be familiar with indications for application, proper technique, and potential pitfalls of casting and splinting to optimize patient care while treating common orthopaedic injuries.

Key words: casting; splinting; application technique; complications

\section{A} Içı ile tespit; acil servislerde ve ortopedi polikliniklerinde, kırık ve çıkıkların geçici veya kalıcı tespiti amacı ile kullanılır. Bunun yanı sıra, yumuşak doku travmaları ve diğer bazı kasiskelet hastalıkları tedavisinde de sıklıkla kullanılan bir yöntemdir. Alçı materyali ile tespit iki temel şekilde uygulanır. Birincisi, alçının daha çok geçici tespit amacı ile kullanıldığı atel (splinting) uygulamasıdır. Dokuyu çevresel olarak sarmadan uygulanan bu yöntem, kolay ve hızlı bir tespite olanak sağlar. Ancak, desteğin tüm dokuda çepeçevre olmaması, hasta uyumunun düşük olmasına ve gereken hareketsizliğin sağlanamamasına yol açar. İkinci uygulama şekli ise daha sıklıkla, kırık ve çıkıkların kalıcı tedavisinde kullanılan sirküler alçı (casting) uygulamasıdır. Çok daha stabil bir tespit sağlayan bu yöntemde, yumuşak doku şişliği, ağrı ve kompartman sendromu gibi komplikasyonlar meydana gelebilir. Atel ya da sirküler alçı ile tespitten en fazla oranda yararlanıp en az komplikasyonla tedaviyi sağlamak için; alçıyı doğru endikasyon, uygun materyaller ve doğru teknik kullanarak yapmak ve istenen tedavi sonucuna ulaşınca en kısa sürede çıkartmak gerekir. ${ }^{[1]} \mathrm{Bu}$ yazıda amaçlanan, uygun materyallerin seçimi ve doğru uygulama tekniklerini vurgulamaktır.

Tüm alçı ile tedavi yöntemlerinde amaç, geçici ya da kalıcı tedaviyi başarı ile sağlarken olası komplikasyonlardan da kaçınmaktır. ${ }^{[1]}$ Bunun için, uygulamayı yapan hekim öncelikle tanıyı doğru koymalıdır. Yaralanmanın şiddetine ve ekstremitenin tedavisi için

- Illetişim adresi: Yusuf Alper Katı, Soğuksu Mah. Kazım Karabekir Caddesi, SBÜ Antalya Eğitim ve Araştırma Hastanesi, Ortopedi ve Travmatoloji Kliniği, Muratpaşa, Antalya Tel: 0505 - 9385599 e-posta: alperkati@gmail.com

- Geliş tarihi: 1 Ağustos 2018 Kabul tarihi: 1 Ağustos 2018 
gerekli olan tespit türüne karar vermeli; uygun tespit seçeneğine karar verdikten sonra hastanın fonksiyonel gereksinimlerini ve olası komplikasyonları gözeterek takip etmelidir. ${ }^{[2]}$ Bu süreçte sadece doğru tanı yeterli olmaz. Aynı zamanda cilt, yumuşak doku, ekstremitenin nörovasküler durumu ve kemik yapılar da dikkatle değerlendirilmelidir. ${ }^{[3]}$

\section{MATERYALLER}

\section{Alçı}

En temel ve ilk kullanım şekliyle alçı (plaster of Paris), acil servislerde ekstremite yaralanmalarında en sık kullanılan tespit materyalidir. ${ }^{[4]}$ İsmini, medikal tedavi amacıyla kireç taşının ısıtılarak hazırlandığı ilk yer olan Paris'ten alır. ${ }^{[5]} 128^{\circ} \mathrm{C}^{\prime}$ ye kadar ısıtılan kireç taşındaki su moleküllerinin neredeyse tümü uçar ve geriye beyaz bir toz kalır (plaster of Paris). Bu toza dışarıdan su eklendiğinde ise bu reaksiyon tersine döner ve ısının ortaya çıkması ile alçı tekrar kristalize olur, moleküler düzeyde kalsiyum sülfat suyla birleşerek örgün bir yapı halini alır ve sertleşir. ${ }^{[5]}$

$\mathrm{Bu}$ alçının günümüzdeki kullanımı ise, ağ şeklinde olan ve alçının uygulanmasını kolaylaştıran, iskelet görevi yapan şerit ya da rulo şeklindeki örgülü materyallere (crinoline-type) emdirilerek sağlanır. Bu şerit ya da rulolar, genellikle $2,3,4,6$ veya 8 inç $(5,7,5,10,15$ ve $20 \mathrm{~cm}$ ) uzunluğundadır ve örgü şeklindeki dokuları sayesinde kolay hazırlama, uygulama ve elle şekillendirebilme olanağı sağlar. ${ }^{[5]}$

\section{Hazır Alçı (Prefabricated Splint)}

Hazır alçı, polipropilen dolgu arasında fiberglas katmanları ile oluşturulan bir alçı türevidir. En önemli özellik ve avantajları, kullanımının kolay, sertleşme süresinin kısa ve hafif olmasıdır. Yaklaşık 3-5 dakikada uygulaması tamamlanan bu alçının klasik alçıya (10-20 dakika arası) göre hazırlık süreci de basittir. ${ }^{[5]}$ Ek olarak, yıkanabilme ve tekrar uygulanabilme özelliği vardır, daha serttir ve ciltte oluşturduğu nemlenme daha azdır. ${ }^{[6]}$ Ancak, diğer tüm alçılara göre pahalıdır. Ayrıca, şekillendirmenin geç yapılıp pozisyonun sonradan verildiği ve geç donmanın isteneceği uygulamalarda, kısa sertleşme süresi nedeniyle uygun olmayabilir.

\section{Alçı Çorabı (Sitokinet)}

Özellikle sirküler alçı uygulaması öncesi ve tek kat uygulanır. Alçı ve pamuk öncesi, cildi koruyucu bir tabaka olarak kullanılır. Ciltte maserasyonu engeller ve uygulanan alçının bitim yerlerinde düzgün sınırlı ve profesyonel görünümlü bir uygulamaya olanak sağlar. ${ }^{[5]}$

\section{Alçı Altı Pamuğu (Padding)}

Alçı altı pamuğu, hem atel uygulaması hem de sirküler alçı uygulaması öncesi, cilt veya alçı çorabı ile alçı arasına uygulanır. Cildi korumanın yanı sıra, özellikle kemik çıkıntılarının (ulnar stiloid, mediyal ve lateral malleol vb.) bası altında kalmasını engeller ve travmaya uğrayan ekstremitede oluşabilecek şişliğin belirli bir ölçüde oluşmasına izin verir.[5] Önceden pamuktan yapılan ve adını buradan alan bu materyal, son zamanlarda işlenmiş fabrikasyon pamuk kullanılarak üretilmeye başlamıştır. Bu sayede, daha esnek ve uygulama sırasında oluşabilecek yırtılmalara daha dayanıklı olmuştur. Ek olarak aynı amaçla, kemik çıkıntılı bölgelere keçe ya da sentetik destekler eklenebilir.

\section{Diğer Materyaller}

Sargı bezi: Sıklıkla atel uygulaması sırasında, atelin ekstremiteye tespitinde kullanilır.

Elastik bandaj: Yine bu amaçla kullanılabilir. Son zamanlarda endüstri, sargı bezi gibi kullanılan, ancak kısmi olarak elastik bandaj gibi baskı yapan materyalleri kullanıma sunmaya başlamıştır.

Ayrıca, sargı bezi ya da elastik bandajı tespit eden bantlar ya da metal klipsler, alçıya şekil vermek, uygun olmayan yerlerini düzeltmek ya da çıkartmak için alçı makasları, özel bıçaklar ve yine alçının kolay çıkartılması için alçı motoru ve çeşitli el aletleri vardır.

\section{SiRKÜLER ALÇI YA DA ATEL TERCiHi}

Sirküler alçı ya da atel, ortopedik yaralanmalarda ya da ekstremiteyi ilgilendiren bazı hastalıklarda sıklıkla kullanılmaktadır (Tablo 1). ${ }^{[5]}$

Alçı ile tespit; kaynamayı, düzgün kemik dizilimini elde etmeyi, ağrının azalmasını ve ekstremiteyi korumayı sağlar. Ancak, uygun olmayan tedavi yöntemleri ya da uzamış tespit süreleri, istenmeyen bazı komplikasyonlara yol açabilir (Tablo 2). Bu nedenle, doğru endikasyon ve teknikte kullanım ile uygun sürede ve sıkı takip, temel gerekliliklerdir. ${ }^{[5]}$

Atel kullanımı daha çok akut ortopedik yaralanmada, basit ve stabil kırıklarda, yumuşak doku yaralanmalarında, tendon-kas hasarında ve kalıcı tedaviye kadar ekstremitenin tespiti için kullanılır.

Atel kullanımının avantajları; yaralanan ekstremiteye hızlı ve kolay uygulanabilir olmasıdır. Hareketin engellenmesi amacı ile statik veya kontrollü harekete izin vermesi amacı ile dinamik olarak uygulanabilir. Sirküler yapıda olmadığı için, yaralanma alanında 
Tablo 1. Atel ya da sirküler alçı kullanım endikasyonları

- Kırıkların geçici ya da kalıcı tespiti

- Eklem çıkıklarının tespiti

- Bağ ve tendon yaralanmaları

- Orta ve ileri yumuşak doku yaralanmaları

- Inflamatuvar hastalıkların ekstremite tutulumları (artrit, tenosinovit, tendinopati vb.)

- Derin cilt yaralanmaları ve ileri açık yumuşak doku hasarları

- Eklem enfeksiyonları

Tablo 2. Atel ve sirküler alçı uygulamalarının komplikasyonları

\begin{tabular}{ll}
\hline - Yanık & - Nörolojik yaralanma \\
- Bası yarası & - Enfeksiyon \\
- Ağrı & - Eklem sertliği \\
- İskemi & - Kompartman sendromu \\
- Cilt enfeksiyonları & - Bölgesel ağrı sendromu
\end{tabular}

oluşan inflamatuvar sürecin doğal bir etkisi olan ödem oluşumunun tolere edilmesini sağlar. Bu nedenle, artmış basınca bağlı oluşabilecek kompartman sendromu ve nekroz gibi ciddi komplikasyonlar açısından, sirküler alçıya göre daha az risk taşır. Yine, uygulama sırasında kolaylıkla çıkartılarak, ekstremitenin kontrolüne ve gözlemine olanak sağlar. ${ }^{[2]}$

Dezavantajları ise; düşük hasta uyumu, yaralı ekstremitede sınırlandırılması istenen hareketin tam olarak sağlanamaması ve instabil parçalı kırıklarda yeterli tespit sağlayamamasıdır.

Sirküler alçı kullanımının, daha etkili tespit sağlaması ve kalıcı tedavide kullanılması gibi avantajları vardır. Ancak buna karşın, uygulama teknik ve takibinde deneyim gerektirmesi ve bazı komplikasyonlara yol açması nedeniyle dezavantajları da vardır.

\section{UYGULAMA PROSEDÜRLERI}

\section{ilk Değerlendirme}

Klinik durum izin verirse, hastanın kıyafetleri alçı ve sudan korunacak şekilde örtülmelidir. ${ }^{[5]}$ Öncelikli olarak, atel ya da sirküler alçı uygulanacak ekstremite dikkatle incelenmeli ve inspeksiyon yapılmalıdır. Özellikle cilt ve yumuşak dokunun durumu ve nörovasküler durum uygulama öncesi dokümante edilmelidir. Tüm yaralar, günlük uygulama pratiğine uygun şekilde temizlenmeli ve kapatılmalıdır. Uygulama tamamlandıktan hemen sonra aynı değerlendirme ve dokümantasyon tekrar yapılmalıdır. ${ }^{[5,7]}$

\section{Atel ya da Sirküler Alçı Öncesi İşlemler}

Atel ya da sirküler alçı uygulamalarında, istenen ekstremite pozisyonu elde edildikten sonrasında ilk uygulanan materyal sıklıkla alçı çorabıdır. Alçı çorabı uygulaması için boy hesaplaması şu şekilde yapılır: Planlanan alçı tipine göre belirlenen alçı mesafesinin (Şekil 1a) her iki tarafından $10 \mathrm{~cm}$ fazlalık hesaplanır ve alçı çorabının boyu belirlenir (Şekil 1b). Alçı çorabının çok sıkı olup dolaşımı etkilemesi ya da bol olup katlantı yaparak ciltte bası oluşturması istenmez. ${ }^{[7]}$ Üst ekstremitede $2-3$ inç $(5-7,5 \mathrm{~cm})$ eninde alt ekstremite içinse 4-6 inç $(10-15 \mathrm{~cm})$ eninde alçı çorabı uygun olur. Fazla bırakılan alçı çorabı, atelin ya da sirküler alçının uygulanması aşamasında alçı üzerine katlanarak düzgün sınırlı bir görüntü oluşturmayı engeller. Ödemin çok fazla olduğu hastalarda, alçı çorabının çevresel olarak ekstremiteyi sarmasından kaçınmak için ve sık ekstremite cilt takibi gerektiren ek yaralanmaların olduğu durumlarda, alçı çorabı kullanılması uygun olmayabilir.

Alçı çorabı uygulaması tamamlandıktan sonra pamuk uygulaması yapılır. Bu uygulamanın amacı, sert alçı yapısı ile ödem nedeniyle hacmi artan cildin arasında yumuşak bir bariyer oluşturmaktır. Ayrıca bu, cildin terlemeye bağlı oluşan maserasyonunu da engeller. ${ }^{[7]}$ Pamuk, uygulanması planlanan alçı boyunun her iki ucundan 2-4 cm uzun olarak sarılır (Şekil 1c). Daha sonra bu fazlalıklar alçının üzerine katlanarak, düzgün sınırlı ve görünüme sahip bir alçı elde etmeyi sağlar. Ekstremiteyi çepeçevre sararak uygulanan pamuk distalden proksimale doğru uygulanır ve pamuğun, her kat bir önceki katın \%25-50'sini örtecek şekilde sarılması önerilir. ${ }^{[5,7]}$ Sıklıkla, önceki katmanın yarısını örterek sarılması, otomatik olarak pamuğun iki katman şeklinde sarılmasını sağlar. Standart uygulamada 2-3 kat uygulanan pamuk, ödemli ve bası etkisi potansiyeli yüksek yaralanmalarda dört kata kadar uygulanabilir. Özellikle üst ekstremitede radyal ve ulnar stiloid ile olekranon çıkıntısı, alt ekstremitede mediyal ve lateral malleol, patella, fibula başı, kalkaneus ve Aşil tendonu üzeri, fazladan pamuk uygulamasına ihtiyaç duyar. Ancak, gereğinden fazla pamuk uygulaması ise stabilite kaybına yol açabilir. ${ }^{[2]}$ Yine, pamuk uygulaması sırasında ayak bileği dorsali, antekübital bölge gibi alanlarda katlantı oluşmasını engellemek için dikkatli olmak gerekir. Ayrıca, pamuk uygulanırken özellikle diz ve dirsek bölgesinde pamuğun yarım bırakılmadan tam geçmesi sağlanmalıdır. Bu amaçla, ekstremitenin nihai pozisyonu verilerek ve tüm aşamalarda bu pozisyon korunarak tespit yapılmalıdır.

Uygulanacak alçı materyali seçiminde önemli diğer bir nokta da alçının sertleşme süresidir. Standart bir alçının sertleşme süresi 10-20 dakikadır. Bunun yanı 

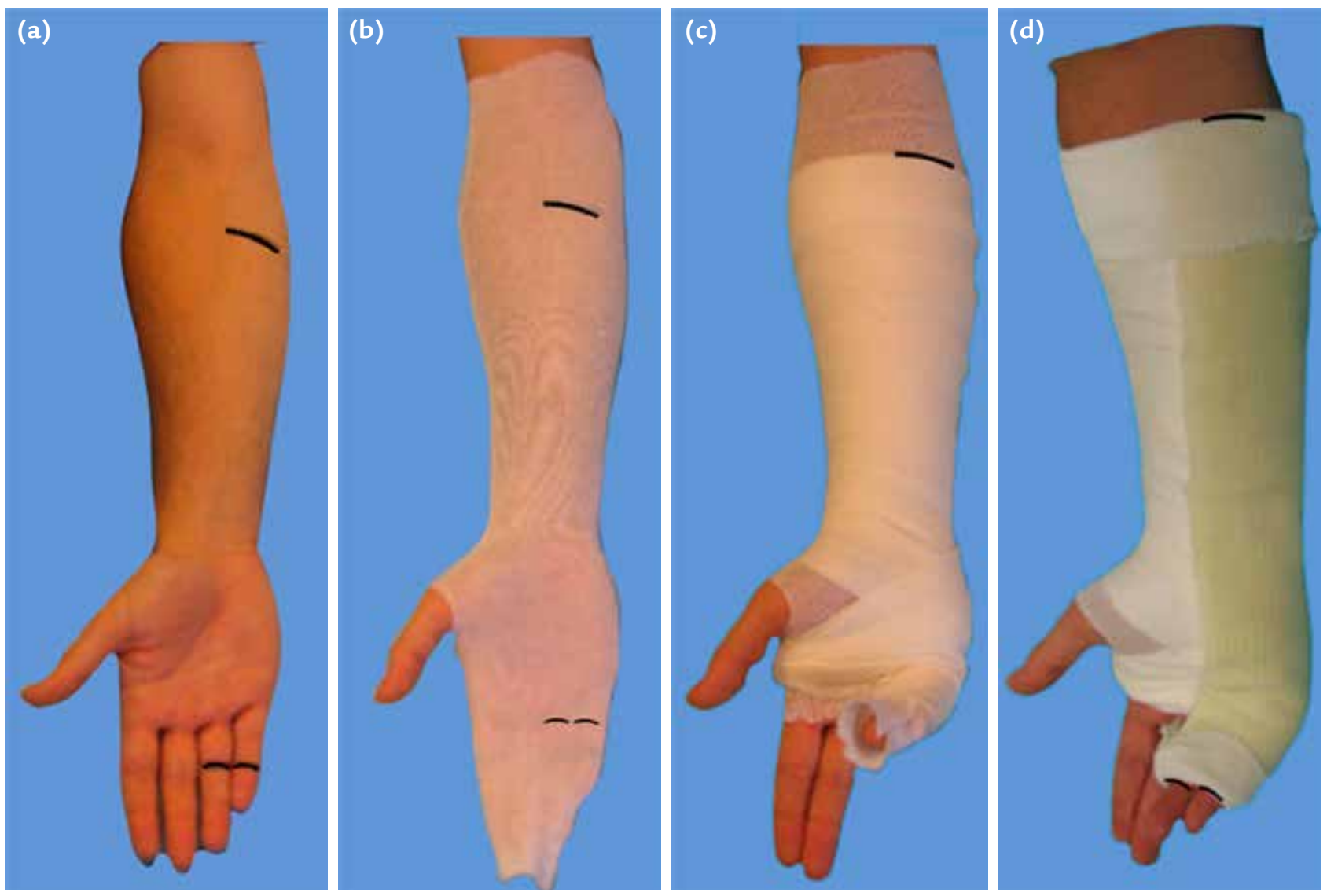

Şekil 1. a-d. Atel uygulanacak ekstremitede uygun atel boyunun belirlenmesi (a). Alçı çorabının uzunluğunun belirlenmesi (b). Alçı altı pamuk boyunun belirlenmesi (c). Uygun boydaki atelin istenen pozisyonda uygulanması ve alçı çorabı ile pamuğun katlanarak, düzgün şekilli atelin elde edilmesi (d).

sıra, özellikle hazır olanlar arasında, hızlı kuruyan (5-8 dakika) ve çok hızlı kuruyan (2-4 dakika) alçılar da vardır. ${ }^{[5]}$ Burada seçim, uygulanacak tespit yöntemi ve klinisyenin tecrübesine göre yapılmalıdır. Hızlı sertleşen alçılar, tespitin kısa sürede sağlanması gereken durumlarda uygundur. Ancak, optimal pozisyonun elde edilmesi için kısa süre gerektiğinden, hasta konforu daha düşük olabilir. Ayrıca, daha yüksek ısıya maruziyet de söz konusudur. Daha yavaş sertleşen alçılar, elle şekil vermeye ve uygun şekle ulaşmaya olanak sağlar ve daha düşük termal yaralanma riski taşır. ${ }^{[8]}$ Aynı özellikteki alçıların sertleşme süreleri de bazı etkenlere bağlı olarak değişkenlik gösterebilir. Bu süreyi en fazla değiştiren etken, suyun sıcaklığıdır. ${ }^{[9]}$ Su sıcaklığı arttıkça daha hızlı sertleşme sağlanırken, tersine, su sıcaklığı azaldıkça sertleşme süresi de uzar. Sertleşme süresini kısaltan diğer nedenler; alçı suyunu yenilemeden tekrar kullanma, tuz ekleme ya da çinko ve magnezyum gibi elementleri eklemedir.

\section{Atel Uygulaması}

Atelin hazırlanması, uygun endikasyona göre atel uzunluğunun belirlenmesi ile başlar. Atel uygulanacak ekstremitenin ne uzunlukta bir atele ihtiyacı olduğunun tespiti, yapılan planlamadaki distal ve proksimal noktalar arasındaki mesafenin ölçümü ile yapılır. Bu ölçüm, uygulamanın yapılacağı ekstremite ya da karşı taraftaki sağlam ekstremite yardımıyla yapılır. Bu mesafeden 1-2 cm daha uzun bir atel hazırlanır (Şekil 1d). Bu fazlalık, anatomik konturların varlığı nedeniyle atelin kısa kalmaması ve alçıyı şekillendirirken ya da kuruma esnasında oluşabilecek kısalmalar içindir. ${ }^{[7]}$ Ekstremiteye uygun ende alçı genişliği ise, hastanın yaşı, ekstremitenin kas veya yağ dokusuna bağlı kalınlığı ve yaralanma miktarına göre değişkenlik gösterir. Bu genellikle üst ekstremite için 2-4 inç $(5-10 \mathrm{~cm})$ iken alt ekstremite için 4-8 inç (10-20 cm)'dir. Doğru boy ve en tespit edildikten sonra, atel üst üste katlanarak ekstremiteye 
destek sağlayacak kalınlıkta hazırlanır. Bu kalınlık, ekstremitenin durumu, hastanın vücut yapısı ve kullanılacak materyale göre değişir. Ortalama olarak, erişkin bir hastada üst ekstremite için 8-12 kat, alt ekstremite içinse 12-16 kat alçı kullanımı yeterli olacaktır. ${ }^{[10]}$ Ancak, bahsedilen değişkenler göz önünde bulundurularak bu rakamlar arttırılabilir ya da azaltılabilir. Daha kalın bir atel yapmak, alçı sertliğini arttırırken, ateli ağır ve hantal bir hale getirecektir. Genel yaklaşım, yeterli tespitin sağlanabileceği en ince ateli uygulamaktır. ${ }^{[11]}$

Atel uygulaması tamamlandıktan sonra, kontrol edilmelidir. İstenen tespitin elde edilip edilmediğine bakılır. Nörovasküler değerlendirme yapılmalı ve hastanın olası bir rahatsızlığı olup olmadığı sorulmalıdır. Yapılan tespit uygun endikasyonda ve teknikte ise, ağrının azalması beklenir. Hastada ağrıda azalma olmaması ya da artış olması durumunda, tüm aşamalar tekrar gözden geçirilmeli ve gerekirse işlem tekrarlanmalıdır. ${ }^{[11]}$

\section{Sirküler Alçı Uygulaması}

Genel olarak atel uygulamasındaki temel prensipler burada da geçerlidir. ${ }^{[2,5]}$ Öncelikle ekstremite hazırlanır ve alçı çorabı ile pamuk uygulanır. Daha sonra, korunması istenen pozisyon verilir ve standart alçı ya da hazır alçı uygulanır. Alçı ekstremiteye sarılırken, pamuk uygulamasındaki gibi bir önceki katmanın yarısını örtecek şekilde sarılır. Alçının fazla sıkılmasından kaçınmak gerekir. Aksi takdirde bu, ciltte ödem ve nörovasküler yapılarda hasara yol açabilir. Tersine, çok fazla pamuk ile sarmak ya da alçıyı gevşek sarmak, tespitte yetersizliğe ve sürtünmeye bağlı cilt hasarına yol açabilir. Alçı tamamen donmadan hedeflenen son posizyon verilmeli ve bu şekilde dondurulmalıdır.

\section{Atel ya da Sirküler Alçı Uygulamasında Diğer Önemli Faktörler}

Alçı için kullanılan su temiz ve taze olmalıdır. Aynı suyun tekrarlanarak kullanılması, sertleşme süresini kısaltır. Su sıcaklığı ile ilgili genel kabul gören değer $24^{\circ} \mathrm{C}$ civarıdır. ${ }^{[5]}$ Bu sıcaklık, alçı ısınmasına bağlı risk oluşturmadan çalışmaya izin veren sıcaklık değeridir. Kuru alçı su altına daldırılır ve hava kabarcıklarının çıkması bitene kadar beklenir. Kabarcıkların tamamen kaybolmasından sonra, alçı sudan çıkartılır ve kibarca sıkılarak ne çok ıslak ne de çok kuru olmayacak şekilde suyu uzaklaştırılır. Atel uygulanacaksa, alçı katmanları sert ve düz bir zemine serilir ve katlantıları kayboluncaya kadar sıvazlanır ve düzgün yüzeyli ve eşit seviyeli bir atel elde edilir. Daha sonra, uygulanacak ekstremiteye mold edilerek tam temas sağlanacak şekilde yerleştirilir. Atel, elastik bandaj ya da sargı bezi ile distalden proksimale doğru sarılır. Son olarak, atelin ya da sirküler alçının katmanları ile pamuk arasında boşluk kalmayacak şekilde elle mold edilerek ekstremiteye nihai pozisyon verilir. ${ }^{[11]}$

Atel ya da sirküler alçı uygulaması sırasında tüm manipülasyonlar, alçı yarı sert bir kıvama gelinceye kadar tamamlanmalıdır. Daha sonrasında yapılacak müdahaleler, alçı içerisindeki kalsiyum sülfat moleküllerinin yetersiz bir kristal bir ağ oluşumuna yol açar ve atelin sertliğini azaltır. Kuruma esnasında alçının örtülmesi havalanmayı engeller ve ısının dışarı çıkmasına da engel olarak sertleşme sürecini uzatır. ${ }^{[5,10]}$

\section{HASTANIN TAKIBi}

Hasta, işlem sonrası takip süreciyle ilişkili, hem yazılı (onam formu) hem de sözlü olarak bilgilendirilmelidir. Elevasyonun ağrının ve ödemin azalmasına olan etkisi anlatılmalı ve hastaya uygun elevasyon pozisyonları gösterilmelidir. Amaç, yaralanan ekstremitenin kalp seviyesinden yukarıda tutulmasıyla venöz dönüşün kolaylaştırılmasıdır. Özellikle ilk 24 saat için en az bir yastık ile elevasyon sağlanmalı ve atel uygulamalarında alçıya soğuk kompres uygulanmalıdır. Soğuk uygulama, kollajeni sertleştirerek tendon ve bağların deforme olmasını engeller. Ayrıca, soğuk uygulama kas spazmını ve kasın uyarılarak ağrının daha fazla hissedilmesini; bunun yanı sıra vasküler akımı azaltarak ödem ve hemorajiyi sınırlar ve inflamasyon yanıtı azaltır. Subkutan dokunun zayıf ısı iletkenliği nedeniyle, soğuk uygulamanın etkisinin oluşabilmesi için en az 30 dakika sürdürülmesi gerekse de; günlük pratik, 20 dakika soğuk uygulama ve 20 dakika ekstremitenin boş kalması şeklindedir. Kırk sekiz saatten daha fazla soğuk uygulamanın kırık bölgesinde hematom oluşumunu sınırlayarak iyileşme dönemini engellemesi nedeniyle, daha fazla soğuk uygulama önerilmez. ${ }^{[11]}$ Alçının sertleşmesi ve sıvı içeriğin buharlaşması devam ettiğinden, alçı ilk 24 saatte tüm darbe ve etkilerden korunmalıdır.

Uygulanan alçı ile ilgili gerekli takip süresi ve yapılması gereken kontrol işlemleri hastaya anlatılmalıdır. Ekstremitenin dolaşımının kontrolü hastalara gösterilmeli, artan ağrı, sonradan oluşan uyuşma ve karıncalanma gibi durumların oluşması ya da kapiller geri-dolumun uzaması ve parmak rengindeki beklenmedik değişikliklerin oluşması halinde, en kısa sürede medikal merkeze kontrole gidilmesi önerilmelidir. Özellikle ilk 2-3 gün bu kontrol ve takip sağlanmalıdır. ${ }^{[1,5,7,12]}$ 


\section{KOMPLIKASYONLAR}

Atel ya da sirküler alçı ile tespit, beraberinde potansiyel komplikasyonları getirir. Bunlar; iskemi, ısınmaya bağlı hasar, bası yaraları, enfeksiyon, cilt sorunları, nörolojik yaralanma ve kompartman sendromu gibi durumlardır. ${ }^{[1,5,7,12,13]}$ Olası bu komplikasyonlar, tespit materyalinin kullanım süresinden bağımsızdır. ${ }^{[14]}$ Yine de, uzun süreli tespit uygulaması, kronik ağrı, eklem sertliği, kas atrofisi ve bölgesel ağrı sendromu gibi tedavisi zor durumlara yol açabilir. Bu komplikasyonlardan en ciddi ve morbidite yaratanı, iskemi zemininde gelişen kompartman sendromudur. ${ }^{[7]}$ Klasik olarak ağrı, şişlik, nabızsızlık, uyuşukluk, bası gibi bulgular gözlense de, en temel ve önemli bulgu, nedeni açıklanamayan ağıı varlığıdır. Özellikle, redüksiyon sonrası azalan ağrının zaman içerisinde kontrolsüz ve klinik ile uyumsuz olarak artışının gözlenmesi çok önemli bir bulgudur. ${ }^{[12]}$ Ancak, ağrı olmadan da kompartman sendromu gelişebileceği akılda tutulmalıdır. Bu gibi durumlarda, mevcut alçının hemen çıkartılarak klinik değerlendirmenin yapılması ve en kısa sürece uygun cerrahi prosedürün uygulanması gerekebilir. Ekzotermik reaksiyonun bir sonucu olarak yanık meydana gelebilir. ${ }^{[9]}$ Özellikle, kemik çıkıntı noktalarının basıya maruz kalması sonucu gelişen cilt basısı yaraları en sık gözlenen komplikasyondur. Bunun önlemini alçılama sırasında almak gerekir. ${ }^{[7]}$ Bakteriyel ya da fungal dermatit gelişimi gözlenebilir. Sıklıkla, açık yaralanmanın olduğu ekstremiteye uygulanan alçı tespiti sonrası gözlenir; ancak uygulanan alçı nedeniyle oluşan nem ve ısının da enfeksiyon gelişimine etkisi çoktur. ${ }^{[15]}$ Eklem sertliği; uzamış alçı tespitinde, yaşlı hastalarda, altta yatan çeşitli artroza bağlı tablolarda daha büyük problem yaratabilen bir durumdur. Bu nedenle, iyileşmenin sağlandığı düşünülen en kısa sürede alçı tespiti çıkartılarak erken harekete başlanmalıdır.

\section{KAYNAKLAR}

1. Boyd AS, Benjamin HJ, Asplund C. Splints and casts: indications and methods. Am Fam Physician 2009;80(5):491-9.

2. Eiff MP, Hatch R, Calmbach $\mathrm{WL}$, editors. Fracture Management for Primary Care 2nd. Ed. Philadelphia, PA: Saunders; 2003:1-70.

3. Reider B, editor. The Orthopaedic Physical Examination. Philadelphia, PA: Saunders; 1999:2-17.

4. Luck JV. Plaster of Paris casts: An experimental and clinical analysis. JAMA 1944;124(1):23. Crossref

5. Chudnofsky CR, Breys S. Splinting Techniques. In: Roberts JR, Hedges JR, Chanmugam AS, editors. Clinical Procedures in Emergency Medicine, 4th ed. Philadelphia, PA: Saunders; 2004. p.989.

6. Ortho-Glass Splinting Manual, Charlotte, NC, Parker Medical Associates, 1994.

7. Boyd AS, Benjamin HJ, Asplund C. Principles of Casting and Splinting. Am Fam Physician 2009;79(1):16-22.

8. GannawayJK, HunterJR. Thermal Effects of Casting Materials. Clin Orthop Relat Res 1983;(181):191-5. Crossref

9. Yap NF, Fisher S. Burns Associated with Plaster of Paris. Presented at the Royal Australasian College of Surgeons. Annual Scientific Congress. Perth 9-13 May 2005.

10. Shaw DC, Heckman JD. Principles and techniques of splinting musculocutaneous injuries. Emerg Med Clin North Am 1984;2(2):391-407.

11. Simon RR, Koenigsknecht SJ, editors. Emergency Orthopaedics: The Extremities. Norwalk, Conn.: Appleton and Lange; 1995. p.3-20.

12. Brown SA, Rajda FE. Orthopaedic Immobilization Techniques. Illinois: Sagamore Publishing; 2015. p.1-12.

13. Fitch MT, Nicks BA, Pariyadath M, McGinnis HD, Manthey DE. Basic Splintig Techniques. N Engl J Med 2008:359(26):e32. Crossref

14. General Principles. In: Simon RR, Sherman SC, Koenigsknecht SJ, editors. Emergency Orthopaedics: The Extremities 5th ed. New York, NY. McGraw-Hill; 2007. p.1-29.

15. Houang ET, Buckley R, Williams RJ, O'Riordan SM. Outbreak of Plaster-Associated Pseudomonas Infection. Lancet 1981;317(8222):728-9. Crossref 